\title{
A TELEVISÃO E AS PRIORIDADES DA EDUCAÇÃO
}

\begin{abstract}
Os meios de comunicação têm responsabilidade com a qualidade do ensino. Inserir a preocupação com a educação na programação normal pode ser um bom começo
\end{abstract}

Contrapondo-se aos números do IBGE - tornados públicos em nível mundial pela Unicef - segundo os quais faltam escolas no Brasil, encontramos os dados revistos por recente pesquisa do Instituto Herbert Levy, da Gazeta Mercantil, sob o título de Ensino Fundamental \& Competividade Empresarial ${ }^{1}$, pelos quais tomamos ciência de que a verdadeira crise da educação reside não na quantidade (na falta de escolas), mas na qualidade da educação oferecida a milhões de brasileiros.

Afirma o estudo que, hoje, do total de crianças de sete aos 14 anos, 95\% matriculam-se na primeira série do primeiro grau. $\mathrm{Ou}$, em outras palavras, apenas $5,3 \%$ da população infanto-juvenil nunca colocarão os pés em uma escola, sendo que $80 \%$ destes residem na região rural miserável do Nordeste. No caso, não estariam faltando escolas. Ao contrário, estariam sobrando vagas nas salas de aulas, dado o fenômeno da contumaz repetência.

\section{O AUTOR}

Ismar de Oliveira Soares

Professor Associado do Departamento de Comunicações e Artes da ECA/USP e Presidente da UCLAP - União Católica Latino-Americana de Imprensa.
Na verdade, os alunos freqüentam a escola de forma descontínua, abandonando-a definitivamente quando se aproximam dos 15 anos, ainda que não tenham alcançado, em média, mais do que a sexta série do primeiro grau.

De acordo com a pesquisa, os graduados levam, em média, 11,4 anos freqüentando a escola de primeiro grau, sendo que os que se evadem, não o fazem antes de permanecerem, em média, 6,4 anos na escola, o que demonstra uma alta persistência das crianças.

Levando em conta, por outro lado, que, para se declarar alguém alfabetizado, faz-se necessário a demonstração de conhecimentos rudimentares assimilados quando o indivíduo conclui pelo menos quatro séries escolares, a pesquisa acaba assinalando que, apesar dos esforços de professores e alunos, o Brasil chegará, finalmente, ao ano 2000 com 41,9 milhões de analfabetos.

\section{EDUCAÇÃO PARA TODOS}

A pesquisa do Instituto Herbert Levy aponta para o fato de que - em nível mundial - o sucesso dos programas educativos depende muito mais do grau de mobilização da sociedade em torno dos objetivos e das práticas da educação do que do empre- 
go de imensas somas de dinheiro no setor. No caso do Brasil, "os maus resultados advêm da falta de empenho que se materializa em descasos de todos os lados"2.

Em 1991, como todos se recordam, reuniram-se, em Brasília, personalidades importantes na vida nacional, representando mais de 100 organizações governamentais, com o objetivo de lançar um manifesto à nação, o pacto pela infância, cujos compromissos incluíam a melhoria do ensino fundamental. Nascia, também e na mesma ocasião, o Plano Decenal de Educação para Todos como fruto de um acordo celebrado no ano anterior, por 159 países, em Jombien, Tailândia, através da Declaração Mundial sobre a Sobrevivência, a Proteção e o Desenvolvimento da Criança nos anos 90, onde se propunha a erradicação total do analfabetismo até o final do século.

O Plano Decenal, elaborado no Brasil com a participação de educadores de mais de $\mathbf{4 5}$ mil escolas, em todo o país, propõe a universalização do ensino com eqüidade e qualidade e a valorização do magistério. O Plano fala, ainda, em parcerias e no fortalecimento de alianças em novos padrões de gestão educacional e no estímulo às inovações ${ }^{3}$.

De modo geral, as pesquisas e os documentos oficiais sobre as carências e as debilidades do ensino têm centrado suas preocupações, suas críticas e suas esperanças na escola, atribuindo ao poder público, através de políticas adequadas, e ao professor, tido ainda como sacerdote ou missionário abnegado, a missão de salvar a educação no Brasil.
Mesmo em estudos como a pesquisa do Instituto Herbert Levy, pouco tem sido dito a respeito de alternativas, entre as quais uma possível participação direta e efetiva do sistema de comunicação social e de seus profissionais na melhoria do ensino no país.

Ao contrário, reforça-se a concepção segundo a qual ao sistema de comunicação cabe, no máximo, um papel coadjuvante de legitimador da escola. Sobre isso, o documento do Instituto afirma, em uma de suas conclusões: aos meios de comunicação de massa caberá tão-somente ações no sentido de obter a adesão dos pais e da sociedade ao fortalecimento do papel social e pedagógico da escola ${ }^{4}$.

A pesquisa não deixa, contudo, de abrir uma janela para o mundo da tecnologia da informação ao recomendar que se desenvolvam propostas visando ao equacionamento dos descompassos existentes entre processos pedagógicos, livros didáticos e as formas modernas de comunicação ${ }^{5}$.

\section{A COMUNICAÇÃO NAS POLÍTICAS DE EDUCAÇÃO}

Em termos das macrodiretrizes governamentais, nenhum documento aproximou mais a área da Educação da área da Comunicação Social que o texto do projeto de Lei de Diretrizes e Bases da Educação Nacional (LDB) de autoria da Câmara dos Deputados.

O projeto de LDB da Câmara dos Deputados - como é do conhecimento público - foi elaborado com o endosso de importantes setores da sociedade civil. É indis-

2. INSTITUTO HERBERT LEVY. Idem, p..28.

3. Janete Martins de Sá, Delegada do MEC em São Paulo, em palestra durante o III Simpósio Brasileiro de Comunicação e Educação, São Paulo, outubro de 1994.

4. INSTITUTO HERBERT LEVY, Idem, p.114.

5. INSTITUTO HERBERT LEVY, Idem, Ibdem. 
pensável lembrar o fato para se ter a certeza de que o grau de preocupação do projeto com a intervenção do Estado na definição de políticas educacionais voltadas à capacitação docente, à educação a distância e ao uso dos meios de comunicação nos processos de ensino-aprendizagem corresponde a um anseio da própria sociedade.

Nesse sentido, é útil recordar o entendimento público, em fase de consolidação, de que a educação não é missão nem trabalho exclusivo da escola e dos profissionais da sala de aula: a própria inter-relação Comunicação Social/Sociedade passou a ser tratada como inter-relação de Educação. Em decorrência, os problemas da educação dizem respeito também ao âmbito do sistema nacional de comunicação.

O texto do projeto de LDB da Câmara compreendeu o tema e o incorporou, de certa forma, quando conferiu ao Sistema Nacional de Ensino a missão de se preocupar tanto com o acompanhamento e a análise dos efeitos dos meios massivos sobre seus usuários quanto com o uso dos recursos da comunicação nos processos de ensinoaprendizagem ${ }^{6}$.

O projeto da Câmara foi mais enfático ao definir os espaços da educação no sistema dos meios, prevendo:

a) a concessão de canais de comunicação ou de informação especialmente voltados à educação a distância;

b) o tratamento diferenciado à educação a distância por parte dos correios, telégrafos, emissoras de rádio e de televisão;

c) a reserva, sem ônus para o Poder Público, pelos concessionários de canais comerciais, de tempo mínimo para a educação a distância; d) o emprego das tecnologias para o aperfeiçoamento do magistério;

e) a disponibilidade de aparelhos e demais condições para a recepção de programas de teleducação no local de trabalho, em empresas e órgãos públicos com mais de 100 empregados;

f) a previsão da presença de especialistas em comunicação educativa em órgãos a serem criados sob a designação do Conselho Nacional de Educação, e no Fórum Nacional de Educação?

$\mathrm{Na}$ mesma linha do texto da LDB da Câmara dos Deputados, o Plano Decenal de Educação para Todos aponta para a urgência de uma efetiva implantação do Sistema Nacional de Educação a Distância, a partir de protocolo celebrado entre o MEC, o Ministério das Comunicações e diversos órgãos oficiais que envolvem, entre outros, os institutos oficiais de ensino superior (as universidades públicas).

O Sistema Nacional de Educação a Distância tem entre seus objetivos aprimorar e ampliar o programa de capacitação e atualização de professores, monitorar e avaliar os programas e projetos de educação a distância, desenvolver projetos de multimeios e de apoio à sala de aula.

Essas ações abrangem o ensino fundamental, a pré-escola, o ensino especial, o ensino médio e tecnológico e também visa dar um suporte para as ações governamentais que dão atenção à criança e ao adolescente.

Alguns dos dispositivos propostos pela sociedade nos projetos analisados começam a ser implantados, como a liberação de

6. Artigo 31 do Projeto de LDB da Câmara dos Deputados. Ver também: SOARES, Ismar de Oliveira. A nova LDB e a formação de profissionais para a inter-relação comunicação/educação. Comunicação \& Educação, São Paulo: CCA/ECAUSP; Moderna, n.2, jan/abr. 1995, p.21-26. (N.E.)

7. Ver sobre o tema: SOARES, Ismar de Oliveira. A Comunicação Social no projeto da nova LDB. Verso e Reverso, São Leopoldo, ano V, n.9, jul/dez 1991, p.71-80. 
um canal exclusivo, em circuito fechado, para a educação a distância, a TV Escola, assim como o programa de valorização do magistério, anunciado pelo Presidente Fernando Henrique Cardoso, em recente pronunciamento à Nação, ainda que discordem do Presidente importantes segmentos do sistema educacional brasileiro.

\section{COMUNICAÇÃO:}

\section{ESPAÇO DE EDUCAÇÃO E CULTURA}

Alguns poderiam entender que dispositivos legais como os que asseguram a educação a distância esgotariam a possível contribuição a ser oferecida pelo Sistema Nacional de Comunicação à melhoria da qualidade da educação, fato que desobrigaria os proprietários dos meios de comunicação de preocuparem-se com o tema.

$\mathrm{Na}$ verdade - em que pesem alguns discursos de oposição - as práticas vigentes no mercado afastam como nefasta e inadequada qualquer idéia que busque um compromisso mais sério e formal entre a Comunicação Social e a Educação.

A Comunicação Social serve para distrair, informar e vender, e basta! Sua linguagem e seu timing são impróprios para o exercício - sempre tedioso - do ensino.

Por outro lado, os custos da produção nestas áreas são muito elevados e a educação não os paga. Além do risco de a audiência rejeitar qualquer mudança na programação das emissoras.

Em consonância com este ideário, um Presidente-jornalista e proprietário de meios massivos - com o apoio de seus colegas, também empresários do setor - suspendeu a Portaria que obrigava os canais de rádio e TV a utilizar com a educação cinco das 168 possíveis horas semanais de suas programações, substituindo-as por spots publicitários encaminhados pelo Ministério da Educação. Para Collor e os concessionários que o ajudaram a ascender ao controle do Governo, cinco horas era tempo demasiado para a educação! Bastariam alguns segundos, distribuídos ao longo da programação!

Está em discussão, pois, o papel educativo dos veículos de comunicação, e que tipo de educação pode ser gestionada a partir dos meios.

A aproximação entre o sistema educativo formal e o mundo da comunicação, quer com a introdução da tecnologia da informação no ambiente escolar, quer com o uso dos meios massivos em projetos educativos adequadamente preparados, precisa deixar de ser a exceção para converter-se na regra.

Educar com e através do rádio, da TV, do jornal, do computador e de todo e qualquer recurso ou veículo de comunicação passa a ser, hoje, questão de exercício e de prática de direitos de cidadania.

Vale lembrar, antes de mais nada, que a educação tem se revelado um "bom negócio". Isto é, o público tem respondido positivamente - comprando os produtos ou oferecendo suas audiências - aos projetos de caráter educativo, de alto nível técnico.

\section{DE UM "BOM NEGÓCIO" A UM "NEGÓCIO BOM"}

É assim que não poucos gerentes de empresas de comunicação têm-se dado conta de que, ao menos por uma questão de marketing, vale a pena investir na educação.

Exemplos são os suplementos que ultimamente vêm acompanhando as edições dominicais dos grandes periódicos e revis- 
tas de circulação nacional: atlas de grande precisão e verdadeiras enciclopédias são colocadas a serviço dos leitores, facilitandolhes o acesso à cultura, num verdadeiro trabalho de apoio ao ensino formal.

Encontram-se difundidos por todo o mundo, com presença também no Brasil, projetos como "O jornal em sala de aula" ou "O jornal na escola", alcançando - com apoio de educadores especialmente preparados - excelente nível pedagógico. Um marketing editorial com resultado educacional.

No campo dos meios audiovisuais, a educação ganhou muito com numerosas experiências de emissão aberta, principalmente no campo do telejornalismo e do documentário. Material de bom nível sobre saúde, meio ambiente, geografia, história, cultura erudita ou popular, literatura brasileira, entre outros domínios da difusão científica, têm sido exibidos.

Ultimamente, a utilização do gênero ficção tem permitido até mesmo às próprias TVs educativas e às Fundações que operam no espaço das TVs comerciais, disputar audiência com as emissões exclusivamente comerciais, num trabalho eminentemente educativo.

Infelizmente, as emissoras reincidem em relegar a horários de fraca audiência o melhor que têm no campo explicitamente educativo. Por outro lado, apesar de sua qualidade, a produção nos campos da documentação e do telejornalismo ou mesmo da ficção, com substratos educativos, são subaproveitados pelo Sistema de Educação. Os professores não têm recursos nem o hábito de gravar os programas, utilizando-os para exibição, leitura crítica e debate em sala de aula.

Voltando ao campo dos meios, resta, contudo, uma pergunta: o que mais poderia ser feito pelas TVs comerciais no campo da educação?
Se a análise depender do jogo do livre mercado, a resposta é simples: nada mais. Se a análise levar em conta a existência de um projeto de emergência que resulte da mobilização nacional em torno da alfabetização universal e da melhoria do nível de educação no país, a resposta será naturalmente outra: há muito o que fazer.

Não cabe, porém, apenas a um partido político ou mesmo a um governo determinar os caminhos a seguir. Mas, sim, à própria sociedade, representada pelos partidos, pelos governos e por organismos não governamentais de reconhecida legitimidade social.

Por isso, causa preocupação quando entidades da sociedade civil vêm a público denunciar o descumprimento de acordos publicamente firmados entre o Governo e a Sociedade em campos delicados e frágeis, como o da educação e o da cultura.

Quando falamos em alfabetização, lembramo-nos imediatamente do caderno pautado, da comunicação escrita. O que deixamos de recordar é que este mesmo aluno — criança, jovem ou adulto - que pela primeira vez pega num lápis para começar a desenhar os primeiros traços já foi, há muito, submerso nas águas batismais da comunicação audiovisual.

Isto é, seguindo a expectativa da qualidade proposta para se avaliar o grau de alfabetização, este ser humano já absorveu os padrões estéticos implantados pelo sistema de meios, assim como já demonstra capacidade de ler o mundo e de formar opinião sobre temas complexos. E, pelo que se supõe, está pautando sua vida, em grande medida, pelas informações que lhe chegam via rádio e televisão. 
Todos os meios educam. Não há dúvida de que existe uma verdadeira pedagogia dos meios. Uma pedagogia do sistema de comunicação. De natureza distinta da pedagogia da escola, mas igualmente responsável pela socialização e pela aprendizagem de quantos com eles mantêm contatos.

A questão que se coloca é: se à sociedade cabe manifestar-se sobre o significado, a natureza e os conteúdos da educação, pergunta-se: em igualdade de condições, não caberia à mesma sociedade manifestar-se quanto às políticas editoriais dos meios, a partir dos objetivos nacionais de educação para todos?

De certa forma, a sociedade já deu uma resposta quando estabeleceu - mediante legislação apropriada - os âmbitos do que denomina meios comerciais e meios educativos. Trata-se de uma distinção inadequada, sob muitos pontos de vista, mas, enfim, realista, tendo em vista os inúmeros interesses que cercam a concessão de canais de rádio e de televisão e o modelo de sustentação financeira destes veículos adotado entre nós.

\section{PAPEL PEDAGÓGICO}

Recorremos, em princípio, ao produtor, pesquisador e professor José Manuel Pérez Tornero, da Universidade Autônoma de Barcelona e um dos estruturadores da TV Educativa da Espanha, autor do livro El Desafio Educativo de la Televisión ${ }^{8}$, para quem a inter-relação Comunicação/Educação não deve limitar-se à formação - pela escola - do receptor crítico ou ao uso esporádico da programação televisiva no ensino. Há, para ele, efetivamente, um espaço para o uso regular do meio nos processos educativos.
Lembramos, inicialmente, que Tornero descarta a idéia da redução do educativo nas TVs culturais apenas às videolecciones (os nossos "telecursos"), uma vez que tal prática não representa outra coisa que a transferência para uma tela de TV dos mesmos procedimentos utilizados no contato presencial entre professor e grupo de alunos.

A TV que interessa à educação é aquela que nossos técnicos e roteiristas, nossos pesquisadores, nossos videomakers e nossos artistas souberam criar e desenvolver, com imaginação, movimento, vida e sedução, ao longo de meio século de aprendizagem?.

\section{Convenção de valores}

Tomamos do mesmo autor as três grandes diferenças por ele propostas como divisores de água entre as TVs comerciais e as educativo-culturais: a convenção de valores; a capacidade de dialogar com a sociedade; o substrato educativo-cultural da programação ${ }^{10}$.

A grande diferença entre uma TV comercial e uma TV educativo-cultural deve ser - para Tornero - a convenção de valores e a finalidade imediata e última: "os valores subjacentes numa televisão educativocultural são os valores do progresso científico, da defesa da cultura, da educação e do diálogo entre as pessoas. No que se refere à finalidade, a televisão educativo-cultural deve contribuir para a formação do telespectador, aumentar sua capacidade crítica, sua formação e, sobretudo, despertar sua consciência"11.

8. TORNERO, José Manuel Pérez. El desafio educativo de la televisión. Barcelona: Paidós, 1994.

9. Ver sobre o assunto: FRANCO, Marilia. Prazer audiovisual. Comunicação \& Educação, nº 2, jan./abr., 1995. p. 49-52. (N.E.)

10. Ver sobre o assunto: CARMONA, Beth et al. Televisão e infância. Comunicação \& Educação, n 5, jan./abr., 1996. p. 109-112. (N.E.)

11. TORNERO, José Manuel Pérez. idem, p. 168. 
No caso, o que se pede de uma TV educativo-cultural não é que ela não deixe de ser televisão, posto que não é escola, mas que ela seja diferente das TVs colocadas prioritariamente a serviço do mercado.

\section{Capacidade de dialogar com a sociedade}

Outro diferencial no caminho da identificação da razão de ser e do trabalho de uma TV educativo-cultural é sua capacidade de dialogar com a população e sua cultura.

Em artigo recente, Mílton Campos ${ }^{12}$ esclarece o que considera o ponto de toque na diferenciação entre uma emissora comercial e um veículo educativo-cultural: o diálogo com o público que a subsidia com seus impostos. Nesse sentido, Mílton Campos aponta para o exemplo da BBC Television, de Londres, que tem padrões de qualidade reconhecidos internacionalmente e que se sente segura o suficiente para discutir-se publicamente, ao promover debates internos (com seus funcionários) e públicos (com seus usuários) sobre seus programas, normatizando, para tanto, os princípios que regem seu trabalho através de inúmeras publicações nas quais estão estruturados seus padrões de excelência ${ }^{13}$.

\section{Substrato educativo-cultural} da programação

Um terceiro diferencial que garante a razão de ser de uma TV educativo-cultural é a existência de um substrato cultural construído com a participação dos educadores e de todo o sistema educativo que bem trabalhado poderia, também, constituir-se em público alvo privilegiado. No caso de São Paulo, temos seis milhões de alunos somente na escola pública. Um público considerável se admitirmos a hipótese de vê-lo multiplicado pela audiência oferecida pelas próprias famílias, entendendo-se que a programação deva permanecer aberta e descompromissada com o rígido esquema da educação formal.

Pelos limites mesmos da capacidade de abordagem e de tratamento temático por parte da escola, tanto professores quanto alunos necessitam de complementação e de atualização. No caso, a escola e o sistema de meios estariam unidos - ainda que caminhando com autonomia - perseguindo um mesmo objetivo: a melhoria rápida da qualidade da educação, revolucionandoa, se for o caso. 